\title{
Return and Volatility Transmission between World-Leading and Latin American Stock Markets: Portfolio Implications
}

\author{
Imran Yousaf ${ }^{1}$, Shoaib Ali ${ }^{1}\left(\mathbb{D}\right.$ and Wing-Keung Wong ${ }^{2,3,4, *(1)}$ \\ 1 Air University School of Management, Air University, Islamabad 44000, Pakistan; \\ imranyousaf_12@pide.edu.pk (I.Y.); shoaibali_12@pide.edu.pk (S.A.) \\ 2 Department of Finance, Fintech Center, and Big Data Research Center, Asia University, Taichung 41354, \\ Taiwan \\ 3 Department of Medical Research, China Medical University Hospital, Taichung 40402, Taiwan \\ 4 Department of Economics and Finance, The Hang Seng University of Hong Kong, Hong Kong 999077, China \\ * Correspondence: wong@asia.edu.tw; Tel.: +886-4-2332-3456
}

Received: 20 May 2020; Accepted: 3 July 2020; Published: 8 July 2020

check for updates

\begin{abstract}
This study uses the BEKK-GARCH model to examine the return-and-volatility spillover between the world-leading markets (USA and China) and four emerging Latin American stock markets over the global financial crisis of 2008 and the crash of the Chinese stock market of 2015. Regarding return spillover, our findings reveal a unidirectional return transmission from Mexico to the US stock market during the global financial crisis. During the crash of the Chinese stock market, the return spillover is found to be unidirectional from the US to the Brazil, Chile, Mexico, and Peru stock markets. Moreover, the results indicate a unidirectional return transmission from China to the Brazil, Chile, Mexico, and Peru stock markets during the global financial crisis and the crash of the Chinese stock market. Regarding volatility spillover, the results show the bidirectional volatility transmission between the US and the stock markets of Chile and Mexico during the global financial crisis. During the Chinese crash, the bidirectional volatility transmission is observed between the US and Mexican stock markets. Furthermore, the volatility spillover is unidirectional from China to the Brazil stock market during the global financial crisis. During the Chinese crash, the volatility spillover is bidirectional between the China and Brazil stock markets. Lastly, a portfolio analysis application has been conducted.
\end{abstract}

Keywords: return spillover; volatility spillover; optimal weights; hedge ratios; US financial crisis; Chinese stock market crash

JEL Classification: G10; G11; G12; G15

\section{Introduction}

The information transmissions (return and volatility) across equity markets are of greater interest to investors and policymakers with increased financial integration all over the world. For example, if asset volatility is transferred from one market to another during turbulence or crisis, then portfolio managers need to adjust their asset allocation (Bouri 2013; Syriopoulos et al. 2015; Yousaf and Hassan 2019) and financial policymakers need to change their policies to reduce the contagion risk (Yang and Zhou 2017). The linkages between equity markets, especially during a crisis, can also have important implications for asset allocations, portfolio diversification, asset valuation, hedging, and risk management.

In the literature, several studies have examined the linkages between equity markets during the Asian crisis of 1997 (In et al. 2001; Chen et al. 2002; Chancharoenchai and Dibooglu 2006; 
Li and Giles 2014; Gulzar et al. 2019) and the global financial crisis (Taşdemir and Yalama 2014; Bekiros 2014; Mensi et al. 2016; Gamba-Santamaria et al. 2017). However, the linkages between equity markets are rarely examined during the crash of the Chinese stock market in 2015. The Chinese stock market crashed in 2015 (Han and Liang 2016; Ahmed and Huo 2019; Yousaf and Hassan 2019). The CSI 300 index had reached up to 5178 points until mid-June in 2015. Then, it took roller-coaster ride and dropped up to $34 \%$ in just 20 days, also losing 1000 points within just one week. Around $50 \%$ of the Chinese stocks lost more than half of their pre-crash market value. This crash adversely affected the many other financial markets around the globe (Fang and Bessler 2017). Despite the importance of the Chinese crash to international portfolio managers, only Ahmed and Huo (2019) examined the volatility transmission between the Chinese and Asian stock markets during the crash of the Chinese stock market in 2015. The empirical research remains surprisingly limited on the area of linkages between equity markets during the crash of the Chinese stock market.

The US and China are the most significant trading partners of the emerging Latin American economies. From 2000 to 2017, the trade volume of China (US) is increased by 21 (2.5)-fold with emerging Latin American economies. The trade volume of leading economies grew at a different rate with the emerging Latin American (LA) economies; thus, spillover can also be changed between the China-LA and US-LA pairs during the last two decades. Johnson and Soenen (2003) also suggest that trade increases the financial integration between countries' stock markets. Previously, several studies have examined the spillovers between the US and Latin American stock markets (Meric et al. 2001; Arouri et al. 2015; Ben Rejeb and Arfaoui 2016; Cardona et al. 2017; Gamba-Santamaria et al. 2017; Ramirez-Hassan and Pantoja 2018; Yousaf and Ahmed 2018; Fortunato et al. 2019; Coleman et al. 2018). However, the linkages between the China and Latin American stock markets have not yet been explored, especially during the global financial crisis and the crash of the Chinese stock market.

Based on the above-mentioned literature gaps, this study aims to examine the return and volatility spillover between the world-leading (the US and China) and emerging Latin American stock markets during the full sample period, the global financial crisis, and the crash of the Chinese stock market. Additionally, this study estimates the optimal weights and hedge ratios during all the sample periods.

Our study makes the following contributions to the literature. First, regarding return spillover, the findings reveal a unidirectional return transmission from Mexico to the US stock market during the global financial crisis. During the crash of the Chinese stock market, the return spillover is found to be unidirectional from the US to the Brazil, Chile, Mexico, and Peru stock markets. Moreover, the results indicate a unidirectional return transmission from China to the Brazil, Chile, Mexico, and Peru stock markets during the global financial crisis and the crash of the Chinese stock market. Regarding volatility spillover, the results show the bidirectional volatility transmission between the US and the stock markets of Chile and Mexico during the global financial crisis. During the Chinese crash, a bidirectional volatility transmission is observed between the US and Mexican stock markets. Furthermore, the volatility spillover is unidirectional from China to the Brazil stock market during the global financial crisis. During the Chinese crash, the volatility spillover is bidirectional between the China and Brazil stock markets.

The contributions of this study are four-fold. First, this study provides a comprehensive analysis of spillover between the world-leading and emerging LA stock markets during the crash of the Chinese stock market. Second, it contributes to the literature of the China-LA stock markets by examining the spillovers during the global financial crisis. Lastly, the BEKK-GARCH model is applied to estimate the spillovers, optimal weights, and hedge ratios, which provide better statistical properties compared to the many other GARCH models. The rest of the paper is organized as follows: Section 2 provides a review of the literature. The empirical method is described in Section 3. Section 4 consists of the data and the preliminary analysis. The empirical results are reported in Section 5 . Finally, Section 5 concludes the discussion. 


\section{Literature Review}

Markowitz's modern portfolio theory can describe the relationship between different stock markets in order to build an optimum portfolio. The rationale behind this concept is to combine risky assets with less risky or risk-free assets in the portfolio (Markovitz 1959). For example, the leading stock market shows a higher volatility during the financial crisis, and as a result the portfolio investors need to diversify their portfolios by investing in weakly integrated emerging stock markets. Therefore, an analysis of risk transmission between different equity markets is essential for portfolio managers to identify opportunities for portfolio diversification across markets and over time.

Over the past decade, there has been a growing body of literature examining the information transmissions (return and volatility) between the US and LA stock markets during the crisis and non-crisis periods. Meric et al. (2001) report significant co-movements between the US and LA (Brazil, Argentina, Chile, and Mexico) stock markets during the period 1984-1995. Fernández-Serrano and Sosvilla-Rivero (2003) report the cointegration across the US and LA equity markets. Sharkasi et al. (2005) investigate the spillover across the US and Brazil stock markets. They provide evidence of co-movements between the US and Brazil stock markets.

Diamandis (2009) investigates the linkages and common trends between the US and four Latin American (Argentina, Brazil, Chile, and Mexico) stock markets. Because the four Latin American countries initiated a phase of financial liberalization in the late 1980s and early 1990s, this study also explores whether the removal of foreign-exchange controls had any effect on the potential linkages. Firstly, this study finds that the US stock market is partially integrated with four LA stock markets. Secondly, the five stock markets have four significant common permanent components/trends which influence their system in the long run. Thirdly, the results indicate significant short-term deviations from standard stochastic patterns during the 1994-1996 Mexican crisis and the 2001 financial crisis.

Beirne et al. (2013) use the tri-variate GARCH-BEKK model to estimate the volatility transmission from mature markets to 41 emerging (including 8 Latin American) stock markets. The volatility transmission is observed to be significant from many mature markets to the emerging stock markets. Additionally, there is evidence of changes in the parameters of volatility spillovers during turbulent or crisis periods. Graham et al. (2012) estimate the integration between the US and 22 emerging equity markets and find evidence of strong co-movements across the US, Brazil, and Mexico equity markets. Hwang (2014) examined the spillover between the US and LA equity markets during the global financial crisis. The study found that the integration between the US and LA equity markets became stronger during the global financial crisis.

Using the VAR-GARCH model, Arouri et al. (2015) estimate the return and volatility transmissions between the US and LA (Brazil, Argentina, Mexico, Chile, and Columbia) stock markets from 1993 through to 2012. The return spillover is seen to be significant from the US to the Argentina, Mexico, and Colombia stock markets. It also provides evidence of a volatility transmission from the US to a few LA stock markets. Syriopoulos et al. (2015) use the VAR-GARCH model and find that the return and volatility spillover is significant between the US and BRICS (Brazil, Russia, India, China, and South Africa) equity markets (at the sectoral level). Mensi et al. (2016) reveal the strong dynamic correlation between US and BRICS equity markets during the global financial crisis of 2008.

Ben Rejeb and Arfaoui (2016) examine the volatility transmission between developed (US and Japan) and emerging (Latin American and Asian) stock markets using standard GARCH models and a quantile regression approach. This study reveals a significant presence of volatility transmission in these markets. The volatility transmission is seen to be closely associated with the crisis period and geographical proximity. A lower and upper quantiles analysis shows that interdependence between markets decreases during a bearish trend, while it increases during bullish markets. Using the GARCH model, Bhuyan et al. (2016) observes return and volatility transmissions from the US to BRICS stock markets.

Al Nasser and Hajilee (2016) provide evidence of short-run integration between developed (US, UK, and Germany) and emerging stock markets (Brazil, Mexico, Russia, China, and Turkey). However, 
in the long run, the cointegration is only found to be significant between Germany and emerging Asian stock markets. Gamba-Santamaria et al. (2017) examine the directional volatility transmission between the US and the four LA stock markets (Brazil, Chile, Mexico, and Columbia) using the framework of Diebold and Yilmaz (2012). Brazil is found to be the net volatility transmitter for most of the sample period, whereas Columbia, Chile, and Mexico are the net receivers of volatility. Moreover, the US stock market is observed to be the net transmitter of volatility to the four LA stock markets. Besides this, the magnitude of volatility transmission is increased from the US to LA stock markets during the global financial crisis of 2008. ${ }^{1}$

Yousaf and Ahmed (2018) study the influence of the US and Brazil on the Mexico, Argentina, Chile, and Peru stock markets by using GARCH in a mean approach. The study concludes that the return effects are dominantly transmitted from the US to the Mexico, Argentina, Chile, and Peru stock markets. Moreover, the volatility transmission is found to be dominant from Brazil to the Mexico, Argentina, Chile, and Peru stock markets. Cardona et al. (2017) use the MGARCH-BEKK model to estimate the volatility transmission between the US and the six LA stock markets (Brazil, Argentina, Mexico, Chile, Peru, and Colombia). They report the significant volatility transmission from the US to all LA stock markets. Moreover, only Brazil transmits volatility effects to the US stock market.

Ramirez-Hassan and Pantoja (2018) provide evidence of co-movements between the returns of the US and six LA stock markets after the global financial crisis of 2008. Fortunato et al. (2019) provide evidence of return transmission from the US to the Brazil, Chile, Columbia, Mexico, and Peru equity markets. Coleman et al. (2018) find the co-movements between the US and LA (Brazil, Chile, Mexico, Peru, Venezuela, and Argentina) stock markets. Su (2020) reports the dominant risk transmission from the G7 (US, Japan, UK, Germany, France, Italy, and Canada) countries to the BRICS (Brazil, Russia, India, China, and South Africa) stock markets.

However, fewer studies have examined the spillovers between the China and Latin American stock markets during the crisis and non-crisis periods. Garza-García and Vera-Juárez (2010) study the impact of US and Chinese macroeconomic variables on the stock markets of Brazil, Mexico, and Chile. The macroeconomic variables (the US and Chinese) are observed to be integrated with the LA stock markets. Additionally, the US macroeconomic variables Granger affect the Brazilian and Mexican stock markets. On the other hand, the Chinese macroeconomic variables Granger affect the stock markets of Mexico and Chile.

Horvath and Poldauf (2012) find that the Chinese stock market is weakly correlated with the Brazil, Australia, Canada, Germany, Japan, Hong Kong, South Africa, Russia, US, and UK stock markets. Sharma et al. (2013) apply the VAR model to examine the linkages between the BRICS (Brazil, Russia, India, China, and South Africa) stock markets. This study finds a return transmission from Brazil (India) to the Russia, India (Brazil), China, and South Africa equity markets. Moreover, the return transmission is only observed from China to the Russian stock market. Bekiros (2014) looks at the contagion effect between Brazil, Russia, India, and China by using several multivariate GARCH models.

1 Our study is different from the study of Gamba-Santamaria et al. (2017) in the following aspects. Gamba-Santamaria et al. (2017) examine the volatility spillover between the US and four Latin American markets (Brazil, Chile, Mexico, and Columbia) during the US financial crisis, whereas our study is examining the volatility as well as return spillover between the leading (US and China) markets and four Latin American markets (Brazil, Chile, Mexico, and Peru) during the US financial crisis and the crash of the Chinese stock market. More specifically, firstly our study examines the return as well as volatility spillovers, whereas Gamba-Santamaria et al. (2017) examine the directional volatility spillovers. Second, our study is examining the spillovers between two world-leading (the US and China) markets and four LA markets, whereas Gamba-Santamaria et al. (2017) examine the spillovers between US and four LA markets. Third, our study is focusing on the spillovers during the global financial crisis and the crash of the Chinese stock market in 2015, whereas Gamba-Santamaria et al. (2017) examine the spillovers during the US financial crisis. Fourth, our study is using the BEKK-GARCH model, whereas Gamba-Santamaria et al. (2017) employ the approach of Diebold and Yilmaz (2012). Lastly, our full data sample is from January 2001 to May 2020, whereas Gamba-Santamaria et al. (2017) use the sample period from January 2003 to January 2016. Apart from the differences, the study of Gamba-Santamaria et al. (2017) is very beneficial for understanding the linkages among the US and LA stock markets. 
This study concludes that there exists a higher integration between Brazil, Russia, India, and China after the global financial crisis.

Ahmad and Sehgal (2015) estimate the volatility of the BRIICKS (Brazil, Russia, India, Indonesia, China, South Korea, and South Africa) stock markets by using the Markov regime-switching (MS) in the mean-variance model. It suggests that investors should allocate investment in the China, Russia, and India emerging stock markets. While investigating the relationship between the Chinese and foreign stock markets (US, Brazil, India, and Germany), Cao et al. (2017) reported a bi-directional causality between the China and foreign stock markets. Previous work does not provide evidence of return and volatility spillover between leading (US and China) and Latin American stock markets during the global financial crisis and the crash of the Chinese stock market. Therefore, this study addresses the above-mentioned literature gaps.

\section{Data and Methodology}

In this section, we will discuss the data and methodology used in our paper. We first discuss the data.

\subsection{Data}

This study uses the daily data of benchmark stock indices of the US (S\&P 500); China (SSE Composite Index); and four emerging LA stock markets-namely, Brazil (IBOVESPA index), Chile (IPSA index), Mexico (S\&P/BMV IPC Index), and Peru (S\&P/BVL Peru General TR PEN Index). The data of stock indices are taken from the Data Stream database. The index is assumed to be the same on non-trading days (holidays except weekends) as on the previous trading day, as suggested by Malik and Hammoudeh (2007), and Ali et al. (2020).

This study uses the full sample period from 1 January 2000, to 29 May 2020, and studies the following two sub-samples: the first sub-period from 1 August 2007, to 30 July 2010, presenting the period with the US financial crisis; and the second sub-period from 1 June 2015, to 31 May 2018, presenting the period with the Chinese stock market crash. We note that Yousaf and Hassan (2019) also use similar timeframes for the global financial crisis and the crash of the Chinese stock market. This study follows He (2001) to use three-year data for each crisis for a short-run analysis. Changes in the market correlations take place continuously, not only as a result of the crises but also due to the consequences of many financial, economic, and political events. This study uses the same time for both the crisis periods to make the coefficient comparable. The difference in the opening time of the China and LA stock markets has been adjusted in the estimations.

\subsection{Methodology}

The econometric specification used in this study has two components. First, a vector autoregression (VAR) with one lag is used to model the returns. ${ }^{2}$ This allows for autocorrelations and cross-autocorrelations in the returns. Second, a multivariate BEKK-GARCH model is used to model the time-varying variances and covariances developed by Engle and Kroner (1995). ${ }^{3}$ BEKK-GARCH has the attractive characteristics that the conditional covariance matrices are positive definite (Chang et al. 2011). Several studies have used the BEKK-GARCH model to estimate the spillover between different asset classes; see, for example, Chang et al. (2011), Sadorsky (2012), Beirne et al. (2013), Chang et al. (2017), Cardona et al. (2017), and Sarwar et al. (2020). Moreover, we will estimate the optimal weights and hedge ratios using the BEKK-GARCH model.

2 The number of lags is selected on the basis of the AIC and SIC criteria.

3 We apply the BEKK-GARCH model on the valuable suggestion of a respected reviewer. 
This study aims to examine the return and volatility spillover between the stock markets, and thus we firstly focus on return spillover. For any pair of two series, the following are the specifications for the conditional mean equation:

$$
R_{t}=\mu+\varnothing R_{t-1}+e_{t} \text { with } e_{t}=H_{t}^{1 / 2} \eta_{t} .
$$

$R_{t}=\left(R_{t}^{x}, R_{t}^{y}\right)^{\prime}$ is the vector of returns on the stock market indices $\mathrm{x}$ and $\mathrm{y}$ at time $t$, respectively; $\varnothing$ is the $2 \times 2$ matrix of parameters, measuring the impacts of own lagged and cross mean transmissions between two series; $e_{t}=\left(e_{t}^{x}, e_{t}^{y}\right)^{\prime}$ is the vector of error terms of the conditional mean equations for the two series at time $t ; \eta_{t}=\left(\eta_{t}^{x}, \eta_{t}^{y}\right)^{\prime}$ indicates a sequence of independently and identically distributed random errors; and $H_{t}=\left(\begin{array}{cc}H_{t}^{x} & H_{t}^{x y} \\ H_{t}^{x y} & H_{t}^{y}\end{array}\right)$ denotes the conditional variance-covariance matrix of return series of $x$ and $y$. In addition, $H_{t}^{1 / 2}$ is the $2 \times 2$ symmetric positive definite matrix.

The full BEKK-GARCH, which imposes positive definiteness restrictions for $H_{t}$, is given by:

$$
H_{t}=C^{\prime} C+A^{\prime} e_{t-1} e_{t-1}^{\prime} A+B^{\prime} H_{t-1} B,
$$

where $A$ and $B$ are $(n \times n)$ coefficient matrices and $C^{\prime} C$ is the decomposition of the intercept matrix. Each element $(i, j)$ th in $H_{t}$ depends on the corresponding $(i, j)$ th element in $\left(e_{t-1} e_{t-1}^{\prime}\right)$ and $H_{t-1}$. Accordingly, past shocks and volatility are allowed to directly spill over from a market to another, and they are captured by the coefficients of the $A$ and $B$ matrices. More specifically, the BEKK-GARCH matrices can be expanded as follows:

$$
\begin{gathered}
h_{t}^{x}=C_{x}+\alpha_{x}^{2}\left(e_{t-1}^{x}\right)^{2}+2 \alpha_{x} \alpha_{y x} e_{t-1}^{x} e_{t-1}^{y}+\alpha_{y x}^{2}\left(e_{t-1}^{y}\right)^{2}+\beta_{x}^{2} h_{t-1}^{x}+2 \beta_{x} \beta_{y x} h_{t-1}^{x y}+\beta_{y x}^{2} h_{t-1}^{y} \\
h_{t}^{x y}=C_{x y}+\alpha_{x} \alpha_{x y}\left(e_{t-1}^{x}\right)^{2}+\left(\alpha_{y x} \alpha_{x y}+\alpha_{x} \alpha_{y}\right) e_{t-1}^{x} e_{t-1}^{y}+\alpha_{y x} a_{y}\left(e_{t-1}^{y}\right)^{2}+\beta_{s} \beta_{x y} h_{t-1}^{x}+\left(\beta_{y x} \beta_{x y}+\beta_{x} \beta_{y}\right) h_{t-1}^{x y}+\beta_{y x} \beta_{y} h_{t-1}^{y} \\
h_{t}^{y}=C_{y}+\alpha_{x y}^{2}\left(e_{t-1}^{x}\right)^{2}+2 \alpha_{x y} \alpha_{y} e_{t-1}^{x} e_{t-1}^{y}+\alpha_{y}^{2}\left(e_{t-1}^{y}\right)^{2}+\beta_{x y}^{2} h_{t-1}^{x}+2 \beta_{x y} \beta_{y} h_{t-1}^{x y}+\beta_{y}^{2} h_{t-1}^{y}
\end{gathered}
$$

The BEKK-GARCH parameters are estimated by the maximum likelihood method using the BFGS algorithm. In addition to the return and volatility spillover, we also compute the optimal weights and hedge ratios for each pair of stocks.

The conditional variance and covariances are used for calculating the optimal portfolio weights and hedge ratios. This study follows Kroner and $\mathrm{Ng}$ (1998) in calculating the optimal portfolio weights of different pairs of stock markets:

$$
\begin{gathered}
w_{t}^{x y}=\frac{h_{t}^{y}-h_{t}^{x y}}{h_{t}^{x}-2 h_{t}^{x y}+h_{t}^{y}}, \\
w_{t}^{x y}=\left\{\begin{array}{c}
0, \text { If } w_{t}^{x y}<0 \\
w_{t}^{x y}, \text { If } 0 \leq w_{t}^{x y} \leq 1 \\
1, \text { If } w_{t}^{x y}>1
\end{array}\right.
\end{gathered}
$$

where $w_{t}^{x y}$ is the weight of $\operatorname{stock}(x)$ in a $\$ 1 \operatorname{stock}(x)$-stock $(y)$ portfolio at time $\mathrm{t} ; h_{t}^{x y}$ is the conditional covariance between the two stock markets; $h_{t}^{x}$ and $h_{t}^{y}$ are the conditional variance of stock $(x)$ and $\operatorname{stock}(y)$, respectively; and $1-w_{t}^{x y}$ is the weight of $\operatorname{stock}(y)$ in a $\$ 1 \operatorname{stock}(x)$-stock $(y)$ portfolio. As suggested by Kroner and Sultan (1993):

$$
\beta_{t}^{x y}=\frac{h_{t}^{x y}}{h_{t}^{y}}
$$

where $\beta_{t}^{x y}$ represents the hedge ratio. This shows that a short position in the stock $(y)$ market can hedge a long position in stock $(x)$. 


\section{Empirical Results and Implications}

In this section, we will discuss our empirical results and implications. We first discuss our preliminary analysis.

\subsection{Descriptive Statistics}

Table 1 reports the summary statistics of the daily returns for the US; China; and four emerging LA stock markets-namely, Brazil, Chile, Mexico, and Peru. Among them, Brazil and Peru have the highest mean return, and the US has the smallest mean return during the full sample period. On the other hand, Chile has the smallest standard deviation, while Brazil has the largest standard deviation. Thus, Peru provides the highest mean return, with a relatively smaller risk in the LA stock markets. Overall, the skewness is significantly negative, the kurtosis is significantly higher than three for all stocks, and the Jarque-Bera statistics reject normality hypothesis for all series, inferring that all the returns are negatively skewed and fat-tailed. Moreover, Table 1 also confirms that there are $1 \%$ significant autocorrelation and $\mathrm{ARCH}$ (autoregressive conditional heteroskedasticity) effects for all returns. We also apply both Augmented Dickey-Fuller (ADF) and Phillip-Perron (PP) tests to examine the stationarity of all the returns and exhibit the results in Table 2. The table indicates that all the series are $1 \%$ significant, inferring that all the returns are stationary.

Table 1. Summary statistics.

\begin{tabular}{cccccccc}
\hline Markets & Mean & Std. Dev. & Skewness & Kurtosis & J-B Stat & Q-Stat & ARCH \\
\hline US & 0.00016 & 0.0124 & $-0.364^{* * *}$ & $14.045^{* * *}$ & $27181.3^{* * *}$ & $56.584^{* * *}$ & $548.40^{* * *}$ \\
CHN & 0.00040 & 0.0155 & $-0.330^{* * *}$ & $8.2116^{* * *}$ & $6121.9^{* * *}$ & $60.119^{* * *}$ & $189.01^{* * *}$ \\
BRAZ & 0.00047 & 0.0183 & $-0.403^{* * *}$ & $9.6439^{* * *}$ & $9937.1^{* * *}$ & $24.957^{* * *}$ & $686.82^{* * *}$ \\
CHIL & 0.00030 & 0.0105 & $-0.878^{* * *}$ & $19.883^{* * *}$ & $37,432.8^{* * *}$ & $148.49^{* * *}$ & $180.34^{* * *}$ \\
MEXI & 0.00024 & 0.0128 & $-0.086^{*}$ & $8.3698^{* * *}$ & $6403.18^{* * *}$ & $108.33^{* * *}$ & $173.49^{* * *}$ \\
PERU & 0.00047 & 0.0133 & $-0.549^{* * *}$ & $15.441^{* * *}$ & $34605.3^{* * *}$ & $290.64^{* * *}$ & $796.97^{* * *}$ \\
\hline
\end{tabular}

Notes: US—United States of America; CHN—China; BRAZ—Brazil; MEXI—Mexico; CHIL—Chile. Q-stat denotes the Ljung-Box Q-statistics. ARCH test refers to the LM-ARCH test. ${ }^{* * *},{ }^{*}$ indicate the statistical significance at $1 \%$ and $10 \%$, respectively.

Table 2. Unit root tests

\begin{tabular}{ccccccc}
\hline & \multicolumn{3}{c}{ ADF $(t$-Test) } & \multicolumn{2}{c}{ Phillips-Perron Test } \\
\hline Markets & None & Constant & $\begin{array}{c}\text { Constant } \\
\text { and Trend }\end{array}$ & None & Constant & $\begin{array}{c}\text { Constant } \\
\text { and Trend }\end{array}$ \\
\hline US & $-79.73^{* * *}$ & $-79.94^{* * *}$ & $-79.96^{* * *}$ & $-80.00^{* * *}$ & $-80.01^{* * *}$ & $-80.05^{* * *}$ \\
CHN & $-32.44^{* * *}$ & $-32.48^{* * *}$ & $-32.49^{* * *}$ & $-69.97^{* * *}$ & $-69.89^{* * *}$ & $-69.88^{* * *}$ \\
BRAZ & $-72.04^{* * *}$ & $-72.08^{* * *}$ & $-72.08^{* * *}$ & $-72.03^{* * *}$ & $-72.08^{* * *}$ & $-72.08^{* * *}$ \\
CHIL & $-33.59^{* * *}$ & $-33.64^{* * *}$ & $-33.67^{* * *}$ & $-63.11^{* * *}$ & $-63.11^{* * *}$ & $-63.10^{* * *}$ \\
MEXI & $-50.70^{* * *}$ & $-50.73^{* * *}$ & $-50.73^{* * *}$ & $-63.67^{* * *}$ & $-63.68^{* * *}$ & $-63.68^{* * *}$ \\
PERU & $-31.06^{* * *}$ & $-31.12^{* * *}$ & $-31.15^{* * *}$ & $-61.82^{* * *}$ & $-61.75^{* * *}$ & $-61.64^{* * *}$ \\
\hline Notes: & US-United States of America; CHN-China; BRAZ-Brazil; MEXI-Mexico; CHIL-Chile; &
\end{tabular}

\subsection{Return and Volatility Spillover between the US and LA Stock Markets}

We turn to apply the BEKK-GARCH model to examine the return and volatility spillovers between the US and LA stock markets in the full sample period, the global financial crisis, and the crash of the Chinese stock market and exhibit the results in Tables $3-5$. We note that the $1 \%$ significant autocorrelation and ARCH effects for all returns, as shown in Table 1, justify the use of the BEKK-GARCH model in our analysis. 
Table 3. Estimates of BEKK-GARCH for the US and Latin American stock markets during the full sample period

\begin{tabular}{|c|c|c|c|c|c|c|c|c|}
\hline \multicolumn{3}{|c|}{ Brazil and US } & \multicolumn{2}{|c|}{ Chile and US } & \multicolumn{2}{|c|}{ Mexico and US } & \multicolumn{2}{|c|}{ Peru and US } \\
\hline \multicolumn{2}{|c|}{ Coefficient } & $p$-Value & Coefficient & $p$-Value & Coefficient & $p$-Value & Coefficient & $p$-Value \\
\hline \multicolumn{9}{|c|}{ Panel A. Mean Equation } \\
\hline$\mu_{1}$ & $0.075^{* * *}$ & 0.000 & $0.098 *$ & 0.062 & $0.058 * * *$ & 0.000 & $0.047^{* * *}$ & 0.000 \\
\hline$\varnothing_{11}$ & $-0.031^{* *}$ & 0.036 & 0.007 & 0.722 & $0.038 * *$ & 0.027 & $0.137^{* * *}$ & 0.000 \\
\hline$\varnothing_{12}$ & $0.023^{* * *}$ & 0.005 & 0.000 & 0.938 & 0.021 & 0.109 & -0.019 & 0.185 \\
\hline$\mu_{2}$ & $0.056^{* * *}$ & 0.000 & $0.062 * * *$ & 0.000 & $0.051 * * *$ & 0.000 & $0.058^{* * *}$ & 0.000 \\
\hline$\varnothing_{21}$ & $0.055^{* *}$ & 0.028 & $0.111^{* * *}$ & 0.000 & $0.050 * * *$ & 0.005 & $0.081 * * *$ & 0.000 \\
\hline$\varnothing_{22}$ & $-0.077^{* * *}$ & 0.000 & $-0.057^{* * *}$ & 0.001 & $-0.071^{* * *}$ & 0.000 & $-0.042^{* * *}$ & 0.006 \\
\hline \multicolumn{9}{|c|}{ Panel B. Variance Equation } \\
\hline$c_{11}$ & $0.219 * * *$ & 0.000 & $2.496^{* * *}$ & 0.000 & $0.117^{* * *}$ & 0.000 & $0.161^{* * *}$ & 0.000 \\
\hline$c_{21}$ & $0.069^{* * *}$ & 0.004 & $0.124^{* * *}$ & 0.009 & $0.050 * * *$ & 0.006 & $0.056^{* * *}$ & 0.003 \\
\hline$c_{22}$ & $0.118^{* * *}$ & 0.000 & 0.042 & 0.571 & $0.124^{* * *}$ & 0.000 & $0.122 * * *$ & 0.000 \\
\hline$\alpha_{11}$ & $0.225^{* * *}$ & 0.000 & 0.003 & 0.562 & $0.264^{* * *}$ & 0.000 & $0.309 * * *$ & 0.000 \\
\hline$\alpha_{12}$ & -0.014 & 0.319 & 0.001 & 0.611 & 0.008 & 0.609 & 0.004 & 0.836 \\
\hline$\alpha_{21}$ & 0.036 & 0.421 & $0.151^{* *}$ & 0.026 & -0.026 & 0.390 & 0.010 & 0.541 \\
\hline$\alpha_{22}$ & $0.338^{* * *}$ & 0.000 & $0.341^{* * *}$ & 0.000 & $0.314^{* * *}$ & 0.000 & $0.300^{* * *}$ & 0.000 \\
\hline$\beta_{11}$ & $0.966^{* * *}$ & 0.000 & $0.701^{* * *}$ & 0.000 & $0.959^{* * *}$ & 0.000 & $0.942^{* * *}$ & 0.000 \\
\hline$\beta_{12}$ & 0.005 & 0.158 & -0.003 & 0.400 & 0.005 & 0.349 & -0.002 & 0.789 \\
\hline$\beta_{21}$ & $-0.101^{* *}$ & 0.050 & 0.095 & 0.203 & $0.090 * *$ & 0.043 & -0.004 & 0.538 \\
\hline$\beta_{22}$ & $0.933^{* * *}$ & 0.000 & $0.944^{* * *}$ & 0.000 & $0.938^{* * *}$ & 0.000 & $0.947^{* * *}$ & 0.000 \\
\hline \multicolumn{9}{|c|}{ Panel C. Diagnostic Tests } \\
\hline $\log L$ & $-16,174.1$ & & $-21,397.4$ & & $-13,816.1$ & & $-14,378.1$ & \\
\hline AIC & 6.789 & & 8.588 & & 5.970 & & 6.370 & \\
\hline SIC & 6.799 & & 8.635 & & 6.017 & & 6.417 & \\
\hline$Q_{1}[20]$ & $30.320 *$ & 0.065 & 1.791 & 0.720 & 19.075 & 0.517 & $328.759 *$ & 0.031 \\
\hline$Q_{2}[20]$ & 18.920 & 0.527 & 19.184 & 0.510 & 19.493 & 0.490 & 17.728 & 0.605 \\
\hline$Q_{1}^{2}[20]$ & 29.942 & 0.182 & 0.004 & 0.659 & $34.776^{* *}$ & 0.021 & 30.071 & 0.198 \\
\hline$Q_{2}^{2}[20]$ & 27.782 & 0.115 & 22.616 & 0.308 & 25.161 & 0.185 & 33.181 & 0.146 \\
\hline
\end{tabular}

Notes: US, United States of America; CHN, China; BRAZ, Brazil; CHIL, Chile; MEXI, Mexico. Variable order is the Latin American stock market (1) and China (2). In the mean equations, $\mu$ denotes the constant terms, whereas $\varnothing_{12}$ denotes the return spillover from the Latin American stock market to the US stock market. In the variance equation, c denotes the constant terms, $\alpha$ denotes the $\mathrm{ARCH}$ terms, and $\beta$ denotes the GARCH terms. In the variance equation, $\alpha_{12}$ indicates the shock spillover from the Latin American stock market to the US stock market, whereas $\beta_{12}$ denotes the long-term volatility spillover from the Latin American stock market to the US stock market. Number of lags for VAR is decided using the SIC and AIC criteria. JB, $Q(20)$, and $Q^{2}(20)$ indicate the empirical statistics of the Jarque-Bera test for normality, Ljung-Box Q statistics of order 20 for autocorrelation applied to the standardized residuals, and squared standardized residuals, respectively. Values in parentheses are the $p$-Value. ${ }^{* * *},{ }^{* *},{ }^{*}$ indicate the statistical significance at $1 \%, 5 \%$, and $10 \%$, respectively.

Tables 3-5 report the return and volatility spillovers between the US and LA stock markets during the full sample period, the global financial crisis, and the crash of the Chinese stock market, respectively. Referring to coefficients $\varnothing_{11}$ and $\varnothing_{22}$ in Panel A, the results show that the lagged returns significantly influence the current returns in the US and the majority of LA stock markets during the full sample period, the global financial crisis, and the crash of the Chinese stock market. It highlights the possibility of the short-term prediction of current returns through past returns in the US and the majority of the LA stock markets. Our results are consistent with the findings of Syriopoulos et al. (2015) and Arouri et al. (2015), which observe a significant impact of past returns on current returns in the US and LA stock markets. 
Table 4. Estimates of BEKK-GARCH for US and Latin American stock markets during the global financial crisis.

\begin{tabular}{|c|c|c|c|c|c|c|c|c|}
\hline & \multicolumn{2}{|c|}{ Brazil and US } & \multicolumn{2}{|c|}{ Chile and US } & \multicolumn{2}{|c|}{ Mexico and US } & \multicolumn{2}{|c|}{ Peru and US } \\
\hline & Coefficient & $p$-Value & Coefficient & $p$-Value & Coefficient & $p$-Value & Coefficient & $p$-Value \\
\hline \multicolumn{9}{|c|}{ Panel A. Mean Equation } \\
\hline$\mu_{1}$ & $0.101 *$ & 0.068 & $0.113^{* * *}$ & 0.000 & 0.055 & 0.246 & -0.014 & 0.744 \\
\hline$\varnothing_{11}$ & -0.044 & 0.450 & $0.118^{* * *}$ & 0.001 & 0.023 & 0.680 & $0.138^{* * *}$ & 0.000 \\
\hline$\varnothing_{12}$ & 0.021 & 0.581 & 0.019 & 0.440 & $0.096^{* *}$ & 0.043 & -0.009 & 0.770 \\
\hline$\mu_{2}$ & 0.019 & 0.665 & 0.046 & 0.361 & 0.064 & 0.144 & 0.029 & 0.518 \\
\hline$\varnothing_{21}$ & 0.040 & 0.578 & 0.020 & 0.308 & 0.020 & 0.707 & 0.063 & 0.107 \\
\hline$\varnothing_{22}$ & $-0.128^{* * *}$ & 0.007 & $-0.164^{* * *}$ & 0.000 & $-0.188^{* * *}$ & 0.000 & $-0.100^{* * *}$ & 0.003 \\
\hline \multicolumn{9}{|c|}{ Panel B. Variance Equation } \\
\hline$c_{11}$ & $0.271^{* *}$ & 0.044 & $0.287^{* * *}$ & 0.000 & $0.218^{* *}$ & 0.017 & $0.291^{* * *}$ & 0.000 \\
\hline$c_{21}$ & 0.098 & 0.546 & 0.040 & 0.417 & -0.035 & 0.730 & $0.173^{* * *}$ & 0.000 \\
\hline$c_{22}$ & $0.129 * *$ & 0.039 & $0.153^{* * *}$ & 0.000 & 0.000 & 0.799 & $0.109 * * *$ & 0.007 \\
\hline$\alpha_{11}$ & $0.421 *$ & 0.069 & $0.483^{* * *}$ & 0.000 & 0.117 & 0.220 & $0.453^{* * *}$ & 0.000 \\
\hline$\alpha_{12}$ & $0.139 * *$ & 0.022 & -0.055 & 0.333 & $-0.104 *$ & 0.057 & 0.087 & 0.255 \\
\hline$\alpha_{21}$ & -0.237 & 0.128 & -0.020 & 0.550 & $0.249^{* * *}$ & 0.000 & -0.088 & 0.581 \\
\hline$\alpha_{22}$ & 0.138 & 0.145 & $0.292 * * *$ & 0.000 & $0.295^{* * *}$ & 0.000 & $0.226^{* * *}$ & 0.002 \\
\hline$\beta_{11}$ & $0.902^{* * *}$ & 0.000 & $0.841^{* * *}$ & 0.000 & $1.063^{* * *}$ & 0.000 & $0.896^{* * *}$ & 0.000 \\
\hline$\beta_{12}$ & $-0.041 *$ & 0.082 & $0.051^{* *}$ & 0.034 & $0.218^{* * *}$ & 0.001 & -0.034 & 0.197 \\
\hline$\beta_{21}$ & 0.071 & 0.482 & 0.024 * & 0.083 & $-0.183^{* * *}$ & 0.000 & 0.014 & 0.687 \\
\hline$\beta_{22}$ & $0.990^{* * *}$ & 0.000 & $0.937^{* * *}$ & 0.000 & $0.797^{* * *}$ & 0.000 & $0.969^{* * *}$ & 0.000 \\
\hline \multicolumn{9}{|c|}{ Panel C. Diagnostic Tests } \\
\hline $\log L$ & -2766 & & -2438.432 & & -2514.181 & & -2804.767 & \\
\hline AIC & 7.792 & & 7.026 & & 7.132 & & 8.025 & \\
\hline $\mathrm{SIC}$ & 8.018 & & 7.253 & & 7.359 & & 8.251 & \\
\hline$Q_{1}[20]$ & 15.405 & 0.753 & 15.396 & 0.753 & 15.749 & 0.732 & 18.138 & 0.578 \\
\hline$Q_{2}[20]$ & 19.980 & 0.459 & 22.469 & 0.316 & 25.023 & 0.201 & 19.998 & 0.458 \\
\hline$Q_{1}^{2}[20]$ & 23.671 & 0.257 & 17.388 & 0.628 & 15.064 & 0.773 & 13.734 & 0.844 \\
\hline$Q_{2}^{2}[20]$ & $37.237 * *$ & 0.011 & $45.203^{* * *}$ & 0.001 & $33.878^{* *}$ & 0.027 & $37.570 * * *$ & 0.010 \\
\hline
\end{tabular}

Notes: US, United States of America; CHN, China; BRAZ, Brazil; CHIL, Chile; MEXI, Mexico. Variable order is the Latin American stock market (1) and China (2). In the mean equations, $\mu$ denotes the constant terms, whereas $\varnothing_{12}$ denotes the return spillover from the Latin American stock market to the US stock market. In the variance equation, c denotes the constant terms, $\alpha$ denotes the $\mathrm{ARCH}$ terms, and $\beta$ denotes the GARCH terms. In the variance equation, $\alpha_{12}$ indicates the shock spillover from the Latin American stock market to the US stock market, whereas $\beta_{12}$ denotes the long-term volatility spillover from the Latin American stock market to the US stock market. Number of lags for VAR is decided using the SIC and AIC criteria. JB, $Q(20)$, and $Q^{2}(20)$ indicate the empirical statistics of the Jarque-Bera test for normality, Ljung-Box Q statistics of order 20 for autocorrelation applied to the standardized residuals, and squared standardized residuals, respectively. Values in parentheses are the $p$-Value. ${ }^{* * *},{ }^{* *},{ }^{*}$ indicate the statistical significance at $1 \%, 5 \%$, and $10 \%$, respectively.

Regarding the interdependence of returns in the mean equation (see coefficients $\varnothing_{12}$ and $\varnothing_{21}$ in Panel A), the results indicate the unidirectional return spillover from the US to the majority of LA stock markets during the full sample period and the crash of the Chinese Stock Market. They imply that the past US returns can be used to predict the current returns of the LA markets during the full sample period and the crash of the Chinese Stock Market. These results are consistent with the previous findings of Arouri et al. (2015), who find the unidirectional return spillover from the US to the LA stock markets. Moreover, the return transmission is also significant from the Brazil to the US stock market during the full sample period. In contrast, the return transmissions are not found to be significant between the US and the majority of the LA stock (except Mexico) markets during the global financial crisis. These results suggest that the US (LA) stock returns are not useful in predicting the returns in the majority of the LA (US) stock markets during the global financial crisis. The results also reveal a unidirectional volatility spillover from Mexico to the US stock market during the global financial crisis.

Based on the variance equation (see coefficients of $\alpha_{11}$ in Panel B), the results show that the conditional volatility of the majority of LA stock markets depends on their past shocks during all the sample periods. In addition, the coefficients of the past own shocks $\left(\alpha_{22}\right)$ are highly significant for the US in all the sample periods. Besides this, the sensitivity of past own volatility $\left(\beta_{11}\right.$ and $\left.\beta_{22}\right)$ is significant for the US and LA stock markets during all the sample periods. These results are consistent 
with the findings of Syriopoulos et al. (2015), which find that the past own volatility is a significant determinant of the future volatility of BRICS countries (including Brazil). Further, the coefficients of past own volatility are higher compared to the coefficients of the past own shocks in the US and LA stock markets, suggesting that the past own volatilities are more critical for the prediction of future volatility than the past own shocks during all the sample periods.

Referring to the coefficient $\alpha_{12}$ and $\alpha_{21}$ in Panel B, the past shocks of the US stock market significantly influence the conditional volatility of just the Chile stock market during the full sample period. During the global financial crisis, the shock transmission is unidirectional from Brazil to the US and bidirectional between the US and Mexican stock markets. Moreover, the conditional volatility of the Mexican stock market is significantly affected by the US during the crash of the Chinese stock market.

Table 5. Estimates of BEKK-GARCH for the US and Latin American stock markets during the crash of the Chinese stock market.

\begin{tabular}{|c|c|c|c|c|c|c|c|c|}
\hline & \multicolumn{2}{|c|}{ Brazil and US } & \multicolumn{2}{|c|}{ Chile and US } & \multicolumn{2}{|c|}{ Mexico and US } & \multicolumn{2}{|c|}{ Peru and US } \\
\hline & Coefficient & $p$-Value & Coefficient & p-Value & Coefficient & p-Value & Coefficient & $p$-Value \\
\hline \multicolumn{9}{|c|}{ Panel A. Mean Equation } \\
\hline$\mu_{1}$ & 0.090 & 0.105 & 0.030 & 0.210 & 0.013 & 0.585 & $0.088^{* *}$ & 0.029 \\
\hline$\varnothing_{11}$ & -0.047 & 0.172 & $0.077^{*}$ & 0.082 & -0.032 & 0.469 & $0.076^{*}$ & 0.089 \\
\hline$\varnothing_{12}$ & 0.016 & 0.302 & -0.035 & 0.134 & 0.002 & 0.937 & -0.025 & 0.550 \\
\hline$\mu_{2}$ & $0.064^{* * *}$ & 0.004 & $0.075^{* * *}$ & 0.001 & $0.072^{* * *}$ & 0.001 & 0.061 & 0.158 \\
\hline$\varnothing_{21}$ & $0.129 *$ & 0.064 & $0.120^{* * *}$ & 0.001 & $0.137^{* * *}$ & 0.000 & $0.086^{*}$ & 0.093 \\
\hline$\varnothing_{22}$ & $-0.066^{* *}$ & 0.040 & -0.052 & 0.112 & $-0.059 *$ & 0.083 & $-0.050 *$ & 0.085 \\
\hline \multicolumn{9}{|c|}{ Panel B. Variance Equation } \\
\hline$c_{11}$ & $0.268^{* * *}$ & 0.005 & $0.361^{* * *}$ & 0.004 & $0.599 * * *$ & 0.000 & 0.159 * & 0.066 \\
\hline$c_{21}$ & $0.151^{* *}$ & 0.017 & 0.011 & 0.720 & $0.164^{* * *}$ & 0.000 & 0.117 & 0.122 \\
\hline$c_{22}$ & 0.124 * & 0.076 & $0.186^{* * *}$ & 0.000 & 0.124 & 0.150 & 0.089 & 0.790 \\
\hline$\alpha_{11}$ & $0.196^{* * *}$ & 0.001 & $0.522^{* * *}$ & 0.001 & $0.434^{* * *}$ & 0.000 & $0.278^{* *}$ & 0.011 \\
\hline$\alpha_{12}$ & 0.008 & 0.821 & -0.024 & 0.326 & 0.033 & 0.298 & 0.142 & 0.331 \\
\hline$\alpha_{21}$ & 0.023 & 0.744 & -0.028 & 0.648 & $-0.115^{*}$ & 0.052 & 0.019 & 0.850 \\
\hline$\alpha_{22}$ & $0.430 * * *$ & 0.000 & $0.421^{* * *}$ & 0.000 & $0.381 * * *$ & 0.000 & 0.313 & 0.416 \\
\hline$\beta_{11}$ & $0.958^{* * *}$ & 0.000 & $0.686^{* * *}$ & 0.001 & $-0.359^{*}$ & 0.077 & $0.949^{* * *}$ & 0.000 \\
\hline$\beta_{12}$ & -0.008 & 0.571 & 0.018 & 0.411 & $-0.068^{* * *}$ & 0.000 & -0.042 & 0.464 \\
\hline$\beta_{21}$ & 0.013 & 0.697 & 0.076 & 0.227 & $0.528^{* * *}$ & 0.000 & -0.014 & 0.766 \\
\hline$\beta_{22}$ & $0.880^{* * *}$ & 0.000 & $0.879^{* * *}$ & 0.000 & $0.915^{* * *}$ & 0.000 & $0.917^{* * *}$ & 0.000 \\
\hline \multicolumn{9}{|c|}{ Panel C. Diagnostic Tests } \\
\hline $\log L$ & -2078 & & -1582.556 & & -1545.033 & & -1733.842 & \\
\hline AIC & 5.759 & & 4.585 & & 4.429 & & 4.891 & \\
\hline SIC & 5.986 & & 4.812 & & 4.655 & & 5.118 & \\
\hline$Q_{1}[20]$ & 21.413 & 0.373 & $33.001 * *$ & 0.034 & 21.955 & 0.343 & $31.804^{* *}$ & 0.045 \\
\hline$Q_{2}[20]$ & 24.907 & 0.205 & 24.713 & 0.213 & 24.601 & 0.217 & 25.783 & 0.173 \\
\hline$Q_{1}^{2}[20]$ & 6.942 & 0.897 & $85.117^{* * *}$ & 0.000 & $29.827 *$ & 0.073 & 16.276 & 0.699 \\
\hline$Q_{2}^{2}[20]$ & 8.249 & 0.890 & 9.945 & 0.969 & 10.383 & 0.961 & 8.909 & 0.984 \\
\hline
\end{tabular}

Notes: US, United States of America; CHN, China; BRAZ, Brazil; CHIL, Chile; MEXI, Mexico. Variable order is the Latin American stock market (1) and China (2). In the mean equations, $\mu$ denotes the constant terms, whereas $\varnothing_{12}$ denotes the return spillover from the Latin American stock market to the US stock market. In the variance equation, $\mathrm{c}$ denotes the constant terms, $\alpha$ denotes the $\mathrm{ARCH}$ terms, and $\beta$ denotes the GARCH terms. In the variance equation, $\alpha_{12}$ indicates the shock spillover from the Latin American stock market to the US stock market, whereas $\beta_{12}$ denotes the long-term volatility spillover from the Latin American stock market to the US stock market. Number of lags for VAR is decided using the SIC and AIC criteria. JB, Q(20), and $Q^{2}(20)$ indicate the empirical statistics of the Jarque-Bera test for normality, Ljung-Box $Q$ statistics of order 20 for autocorrelation applied to the standardized residuals, and squared standardized residuals, respectively. Values in parentheses are the $p$-Value. ${ }^{* * *},{ }^{* *},{ }^{*}$ indicate the statistical significance at $1 \%, 5 \%$, and $10 \%$, respectively.

Regarding the cross-market volatility spillover (see coefficients $\beta_{12}$ and $\beta_{21}$ in Panel B), the results indicate that the volatility transmission is unidirectional from the US to the Brazil and Mexican stock markets during the full sample period. In contrast, the results reveal the bidirectional volatility transmission between the US and two LA stock markets (Chile and Mexico), whereas there was unidirectional volatility transmission from Brazil to the US stock market during the global financial crisis. 
These results are in contrast with the findings of Wang et al. (2017), which report an insignificant volatility spillover between the US and Brazil stock markets during the global financial crisis. The considerable trade volumes between the US and two LA stock markets (Brazil and Mexico) explain the volatility linkages between the stock markets of the concerned countries. Johnson and Soenen (2003) also suggest that trade increases the financial contagion effects between the stock markets of concerned countries. From the Latin American region, Mexico is the biggest trading partner of the US; therefore, volatility linkages are also observed between Mexico and the US stock market during the global financial crisis. These findings suggest that portfolio investors can get the maximum benefit of diversification by making a portfolio of US and Peru stocks during the global financial crisis. Lastly, a bidirectional volatility transmission is observed between the US and Mexican stock markets during the crash of the Chinese stock market. It implies that portfolio investors can diversify risk by making a portfolio of the US and LA stock markets (except Mexico) during the crash of the Chinese stock market.

\subsection{Return and Volatility Spillover between China and the LA Stock Markets}

Tables 6-8 represent the return and volatility transmissions between China and the LA stock markets during the full sample period, the global financial crisis, and the crash of the Chinese stock market. The difference in the opening time of the China and LA stock markets has been adjusted where necessary in the estimations. Referring to the coefficient $\varnothing_{11}$ in Panel A, the results indicate that the lagged returns of the majority of LA stock markets (except Brazil) largely determine their current returns during the full sample period and the crash of the Chinese stock market. During the global financial crisis, the past returns significantly affect the current returns of the Chile and Peru stock markets. This implies that the past returns can be used for the short-term prediction of the current LA stock returns. These results confirm the previous findings of Arouri et al. (2015). Referring to the coefficient $\varnothing_{22}$ in Panel A, the lagged returns significantly influence the current returns in the Chinese stock market during the full sample period. In contrast, the current returns of the Chinese stock market are not influenced by their past returns during the global financial crisis and the crash of the Chinese stock market. This implies that the past returns cannot be used for the short-term prediction of the current Chinese stock returns during the crisis period.

Based on the cross-market return spillover (see the coefficients $\varnothing_{12}$ and $\varnothing_{21}$ in Panel A), the results reveal the unidirectional return transmissions from China to the majority of LA stock markets during all the sample periods. These results contradict the previous findings of Aktan et al. (2009) and Sharma et al. (2013), who report the insignificant impact of the Chinese stock returns on the Brazilian stock returns. In addition, the return transmission is also significant from Brazil to China during the crash of the Chinese stock market.

From the variance equation (see coefficients $\alpha_{11}$ and $\alpha_{22}$ Panel B), the findings show that the lagged shocks significantly influence the conditional volatility of the China and LA stock markets during all the sample periods. Referring to the coefficients $\beta_{11}$ and $\beta_{22}$, the results show that the current conditional volatility depends on their past volatility in the China and LA stock markets during the all sample periods. The critical finding is that the coefficients of past own volatility are seen to be higher compared to the past own shocks. This difference suggests that past own volatilities rather than past shocks are more important for the prediction of the current volatility in the China and LA stock markets.

Refer to the coefficients $\alpha_{12}$ and $\alpha_{21}$ in panel $\mathrm{B}$, the shock transmission is unidirectional from Brazil and Peru to the Chinese stock market, whereas bidirectional shock transmission is observed between the China and Mexican stock markets during the full sample period. The results reveal that the past shocks in the Brazil and Mexican stock markets significantly affect the conditional volatility of the Chinese stock market during the global financial crisis. On the other hand, the shock spillover is insignificant between China and the majority of the LA stock markets during the crash of the Chinese stock market. 
Table 6. Estimates of BEKK-GARCH for the China and Latin American stock markets during the full sample period.

\begin{tabular}{|c|c|c|c|c|c|c|c|c|}
\hline & \multicolumn{2}{|c|}{ Brazil and China } & \multicolumn{2}{|c|}{ Chile and China } & \multicolumn{2}{|c|}{ Mexico and China } & \multicolumn{2}{|c|}{ Peru and China } \\
\hline & Coefficient & $p$-Value & Coefficient & $p$-Value & Coefficient & p-Value & Coefficient & p-Value \\
\hline \multicolumn{9}{|c|}{ Panel A. Mean Equation } \\
\hline$\mu_{1}$ & $0.076^{* * *}$ & 0.001 & $0.047^{* * *}$ & 0.000 & $0.038^{* * *}$ & 0.004 & $0.050 * * *$ & 0.000 \\
\hline$\varnothing_{11}$ & $0.033^{* *}$ & 0.050 & $0.205^{* * *}$ & 0.000 & $0.101^{* * *}$ & 0.000 & $0.234^{* * *}$ & 0.000 \\
\hline$\varnothing_{12}$ & 0.013 & 0.208 & 0.020 & 0.190 & 0.014 & 0.213 & 0.015 & 0.287 \\
\hline$\mu_{2}$ & $0.044^{* * *}$ & 0.008 & $0.042^{* *}$ & 0.026 & $0.050 * * *$ & 0.000 & $0.039 * *$ & 0.045 \\
\hline$\varnothing_{21}$ & $0.132 * * *$ & 0.000 & $0.036^{* * *}$ & 0.000 & $0.075^{* * *}$ & 0.000 & $0.053^{* * *}$ & 0.000 \\
\hline$\varnothing_{22}$ & $0.037^{* * *}$ & 0.005 & $0.041^{* *}$ & 0.019 & $0.036^{* *}$ & 0.011 & $0.042^{* * *}$ & 0.009 \\
\hline \multicolumn{9}{|c|}{ Panel B. Variance Equation } \\
\hline$c_{11}$ & $0.283^{* * *}$ & 0.000 & $0.186^{* * *}$ & 0.000 & $0.138^{* * *}$ & 0.000 & $0.219^{* * *}$ & 0.000 \\
\hline$c_{21}$ & 0.009 & 0.699 & -0.001 & 0.956 & 0.009 & 0.721 & -0.013 & 0.500 \\
\hline$c_{22}$ & $0.118^{* * *}$ & 0.000 & $0.121^{* * *}$ & 0.000 & $0.115^{* * *}$ & 0.000 & $0.108^{* * *}$ & 0.000 \\
\hline$\alpha_{11}$ & $0.273^{* * *}$ & 0.000 & $0.347^{* * *}$ & 0.000 & $0.279 * * *$ & 0.000 & $0.394^{* * *}$ & 0.000 \\
\hline$\alpha_{12}$ & $-0.023 *$ & 0.059 & 0.013 & 0.490 & $-0.037^{* * *}$ & 0.002 & $-0.024 *$ & 0.057 \\
\hline$\alpha_{21}$ & 0.000 & 0.899 & 0.001 & 0.950 & $0.021 *$ & 0.087 & -0.002 & 0.920 \\
\hline$\alpha_{22}$ & $0.250 * * *$ & 0.000 & $0.243^{* * *}$ & 0.000 & $0.240^{* * *}$ & 0.000 & $0.237^{* * *}$ & 0.000 \\
\hline$\beta_{11}$ & $0.948^{* * *}$ & 0.000 & $0.919^{* * *}$ & 0.000 & $0.954^{* * *}$ & 0.000 & $0.904^{* * *}$ & 0.000 \\
\hline$\beta_{12}$ & $0.015^{* *}$ & 0.040 & -0.002 & 0.741 & $0.009^{* * *}$ & 0.003 & $0.015^{* * *}$ & 0.007 \\
\hline$\beta_{21}$ & 0.002 & 0.814 & 0.002 & 0.726 & -0.004 & 0.283 & 0.001 & 0.840 \\
\hline$\beta_{22}$ & $0.966^{* * *}$ & 0.000 & $0.968^{* * *}$ & 0.000 & $0.969^{* * *}$ & 0.000 & $0.970^{* * *}$ & 0.000 \\
\hline \multicolumn{9}{|c|}{ Panel C. Diagnostic Tests } \\
\hline $\log L$ & $-19,187.432$ & & $-15,839.650$ & & $-17,037.161$ & & $-16,739.334$ & \\
\hline AIC & 7.720 & & 6.599 & & 7.002 & & 7.045 & \\
\hline SIC & 7.767 & & 6.646 & & 7.049 & & 7.092 & \\
\hline$Q_{1}[20]$ & 21.935 & 0.344 & 19.993 & 0.458 & 17.078 & 0.648 & $72.725^{* * *}$ & 0.000 \\
\hline$Q_{2}[20]$ & $82.861^{* * *}$ & 0.000 & $78.794^{* * *}$ & 0.000 & $83.815^{* * *}$ & 0.000 & $80.555^{* * *}$ & 0.000 \\
\hline$Q_{1}^{2}[20]$ & 26.742 & 0.133 & 8.890 & 0.984 & 26.056 & 0.187 & 18.240 & 0.572 \\
\hline$Q_{2}^{2}[20]$ & 22.787 & 0.299 & 22.412 & 0.319 & 25.134 & 0.196 & 25.146 & 0.196 \\
\hline
\end{tabular}

Notes: US, United States of America; CHN, China; BRAZ, Brazil; CHIL, Chile; MEXI, Mexico. Variable order is the Latin American stock market (1) and China (2). In the mean equations, $\mu$ denotes the constant terms, whereas $\varnothing_{12}$ denotes the return spillover from the Latin American stock market to the Chinese stock market. In the variance equation, $\mathrm{c}$ denotes the constant terms, $\alpha$ denotes the ARCH terms, and $\beta$ denotes the GARCH terms. In the variance equation, $\alpha_{12}$ indicates the shock spillover from the Latin American stock market to the Chinese stock market, whereas $\beta_{12}$ denotes the long-term volatility spillover from the Latin American stock market to the Chinese stock market. Number of lags for VAR is decided using the SIC and AIC criteria. JB, Q(20), and $Q^{2}(20)$ indicate the empirical statistics of the Jarque-Bera test for normality, Ljung-Box Q statistics of order 20 for autocorrelation applied to the standardized residuals, and squared standardized residuals, respectively. Values in parentheses are the $p$-Value. ${ }^{* * *}, * *, *$ indicate the statistical significance at $1 \%, 5 \%$, and $10 \%$, respectively.

Based on the cross-market volatility spillover effects (see coefficients $\beta_{12}$ and $\beta_{21}$ in Panel B), the results demonstrate that there is unidirectional volatility transmission from Brazil, Mexico, and Peru to China during the full sample period. These volatility transmissions can be explained through the considerable trading volumes between China and two Latin economies (Brazil and Mexico) during the full sample period. During the global financial crisis, the volatility effects are transmitted from the China to Brazil stock markets. Therefore, the majority of LA stock markets provide an opportunity to diversify the risk of Chinese equity portfolios during the global financial crisis. Lastly, the volatility spillover is bidirectional between the China and Brazil stock markets during the crash of the Chinese stock market. Due to the crash of the Chinese stock market, the slowdown of the Chinese economy also affected its major trading partner Brazil and its stock market; therefore, volatility linkages are also observed between China and Brazil. These findings propose that the portfolio investors of Chinese stock markets can get the maximum benefit of diversification by adding Mexico, Chile, and Peru stocks in their portfolios during the crash of the Chinese stock market. 
Table 7. Estimates of BEKK-GARCH for the China and Latin American stock markets during the global financial crisis.

\begin{tabular}{|c|c|c|c|c|c|c|c|c|}
\hline & \multicolumn{2}{|c|}{ BRAZIL and China } & \multicolumn{2}{|c|}{ Chile and China } & \multicolumn{2}{|c|}{ Mexico and China } & \multicolumn{2}{|c|}{ Peru and China } \\
\hline & Coefficient & $p$-Value & Coefficient & $p$-Value & Coefficient & $p$-Value & Coefficient & $p$-Value \\
\hline \multicolumn{9}{|c|}{ Panel A. Mean Equation } \\
\hline$\mu_{1}$ & $0.106^{*}$ & 0.081 & $0.116^{* * *}$ & 0.001 & 0.035 & 0.476 & 0.014 & 0.773 \\
\hline$\varnothing_{11}$ & 0.029 & 0.465 & $0.195^{* * *}$ & 0.000 & 0.034 & 0.340 & $0.211^{* * *}$ & 0.000 \\
\hline$\varnothing_{12}$ & -0.003 & 0.938 & -0.073 & 0.189 & -0.034 & 0.424 & -0.023 & 0.554 \\
\hline$\mu_{2}$ & 0.044 & 0.590 & 0.001 & 0.987 & 0.090 & 0.285 & 0.030 & 0.731 \\
\hline$\varnothing_{21}$ & $0.186^{* * *}$ & 0.000 & 0.030 * & 0.083 & $0.101 * * *$ & 0.000 & $0.103^{* * *}$ & 0.000 \\
\hline$\varnothing_{22}$ & 0.032 & 0.422 & 0.022 & 0.572 & 0.033 & 0.431 & 0.027 & 0.488 \\
\hline \multicolumn{9}{|c|}{ Panel B. Variance Equation } \\
\hline$c_{11}$ & -0.201 & 0.105 & $0.142^{* *}$ & 0.025 & $0.127^{* * *}$ & 0.008 & $0.344^{* * *}$ & 0.000 \\
\hline$c_{21}$ & 0.134 & 0.577 & $1.932^{* * *}$ & 0.000 & 0.134 & 0.479 & 0.081 & 0.250 \\
\hline$c_{22}$ & 0.143 & 0.385 & 0.000 & 0.920 & $0.195^{* *}$ & 0.037 & $0.163 *$ & 0.098 \\
\hline$\alpha_{11}$ & $0.297^{* * *}$ & 0.000 & $0.408^{* * *}$ & 0.000 & $0.253^{* * *}$ & 0.000 & $0.477^{* * *}$ & 0.000 \\
\hline$\alpha_{12}$ & -0.041 & 0.409 & -0.108 & 0.124 & -0.041 & 0.392 & -0.005 & 0.902 \\
\hline$\alpha_{21}$ & -0.069 * & 0.089 & 0.007 & 0.686 & $0.060 * *$ & 0.020 & -0.031 & 0.215 \\
\hline$\alpha_{22}$ & $0.188^{* * *}$ & 0.001 & $0.316^{* * *}$ & 0.000 & $0.209^{* * *}$ & 0.000 & $0.181^{* * *}$ & 0.000 \\
\hline$\beta_{11}$ & $0.947^{* * *}$ & 0.000 & $0.893^{* * *}$ & 0.000 & $0.960 * * *$ & 0.000 & $0.870^{* * *}$ & 0.000 \\
\hline$\beta_{12}$ & 0.006 & 0.580 & 0.021 & 0.130 & 0.003 & 0.820 & 0.005 & 0.777 \\
\hline$\beta_{21}$ & $0.028 *$ & 0.085 & 0.047 & 0.260 & -0.009 & 0.292 & 0.005 & 0.515 \\
\hline$\beta_{22}$ & $0.977^{* * *}$ & 0.000 & -0.259 & 0.143 & $0.972 * * *$ & 0.000 & $0.979^{* * *}$ & 0.000 \\
\hline \multicolumn{9}{|c|}{ Panel C. Diagnostic Tests } \\
\hline $\log L$ & -3318.981 & & -2879.180 & & -3090.113 & & -3166.538 & \\
\hline AIC & 8.973 & & 7.826 & & 8.388 & & 8.689 & \\
\hline SIC & 9.200 & & 8.052 & & 8.614 & & 8.915 & \\
\hline$Q_{1}[20]$ & 14.730 & 0.792 & 11.805 & 0.923 & 17.935 & 0.592 & 17.407 & 0.626 \\
\hline$Q_{2}[20]$ & 30.922 * & 0.056 & $32.099 * *$ & 0.042 & 30.614 * & 0.060 & 31.335 * & 0.051 \\
\hline$Q_{1}^{2}[20]$ & 22.021 & 0.339 & 12.016 & 0.916 & 14.074 & 0.827 & 9.990 & 0.968 \\
\hline$Q_{2}^{2}[20]$ & 28.559 & 0.127 & 37.567 & 0.161 & 26.806 & 0.141 & 28.213 & 0.104 \\
\hline \multicolumn{9}{|c|}{$\begin{array}{l}\text { Notes: US, United States of America; CHN, China; BRAZ, Brazil; CHIL, Chile; MEXI, Mexico. Variable order } \\
\text { is the Latin American stock market (1) and China (2). In the mean equations and } \mu \text { denotes the constant terms, } \\
\text { whereas } \varnothing_{12} \text { denotes the return spillover from the Latin American stock market to the Chinese stock market. In the } \\
\text { variance equation, c denotes the constant terms, } \alpha \text { denotes the ARCH terms, and } \beta \text { denotes the GARCH terms. In } \\
\text { the variance equation, } \alpha_{12} \text { indicates the shock spillover from the Latin American stock market to the Chinese stock } \\
\text { market, whereas } \beta_{12} \text { denotes the long-term volatility spillover from the Latin American stock market to the Chinese } \\
\text { stock market. Number of lags for VAR is decided using the SIC and AIC criteria. JB, Q(20), and } \mathrm{Q}^{2}(20) \text { indicate } \\
\text { the empirical statistics of the Jarque-Bera test for normality, Ljung-Box } \mathrm{Q} \text { statistics of order } 20 \text { for autocorrelation } \\
\text { applied to the standardized residuals, and squared standardized residuals, respectively. Values in parentheses are } \\
\text { the } p \text {-Value. }{ }^{* * *},{ }^{* *},{ }^{*} \text { indicate the statistical significance at } 1 \%, 5 \% \text {, and } 10 \% \text {, respectively. } \\
\text { Table } 8 \text {. Estimates of BEKK-GARCH for the China and Latin American stock markets during the crash } \\
\text { of the Chinese stock market. }\end{array}$} \\
\hline & \multicolumn{2}{|c|}{ BRAZIL and China } & \multicolumn{2}{|c|}{ Chile and China } & \multicolumn{2}{|c|}{ Mexico and China } & \multicolumn{2}{|c|}{ Peru and China } \\
\hline & Coefficient & p-Value & Coefficient & $p$-Value & Coefficient & $p$-Value & Coefficient & p-Value \\
\hline \multicolumn{9}{|c|}{ Panel A. Mean Equation } \\
\hline$\mu_{1}$ & 0.055 & 0.282 & 0.039 * & 0.063 & 0.008 & 0.765 & 0.059 * & 0.087 \\
\hline$\varnothing_{11}$ & 0.036 & 0.292 & $0.181^{* * *}$ & 0.000 & $0.077^{* *}$ & 0.017 & $0.229 * * *$ & 0.000 \\
\hline$\varnothing_{12}$ & $0.043^{* *}$ & 0.048 & 0.026 & 0.350 & 0.012 & 0.791 & 0.033 & 0.333 \\
\hline$\mu_{2}$ & 0.022 & 0.495 & 0.020 & 0.474 & 0.020 & 0.420 & 0.022 & 0.410 \\
\hline$\varnothing_{21}$ & $0.105^{* * *}$ & 0.001 & $0.057^{* * *}$ & 0.001 & $0.074^{* * *}$ & 0.000 & $0.062^{* * *}$ & 0.003 \\
\hline$\varnothing_{22}$ & 0.032 & 0.360 & 0.040 & 0.228 & 0.039 & 0.255 & 0.026 & 0.470 \\
\hline
\end{tabular}


Table 8. Cont.

\begin{tabular}{|c|c|c|c|c|c|c|c|c|}
\hline & \multicolumn{2}{|c|}{ BRAZIL and China } & \multicolumn{2}{|c|}{ Chile and China } & \multicolumn{2}{|c|}{ Mexico and China } & \multicolumn{2}{|c|}{ Peru and China } \\
\hline & Coefficient & p-Value & Coefficient & $p$-Value & Coefficient & p-Value & Coefficient & $p$-Value \\
\hline \multicolumn{9}{|c|}{ Panel A. Mean Equation } \\
\hline$\mu_{1}$ & 0.055 & 0.282 & $0.039 *$ & 0.063 & 0.008 & 0.765 & $0.059 *$ & 0.087 \\
\hline$\varnothing_{11}$ & 0.036 & 0.292 & $0.181^{* * *}$ & 0.000 & $0.077^{* *}$ & 0.017 & $0.229 * * *$ & 0.000 \\
\hline$\varnothing_{12}$ & $0.043^{* *}$ & 0.048 & 0.026 & 0.350 & 0.012 & 0.791 & 0.033 & 0.333 \\
\hline$\mu_{2}$ & 0.022 & 0.495 & 0.020 & 0.474 & 0.020 & 0.420 & 0.022 & 0.410 \\
\hline$\varnothing_{21}$ & $0.105^{* * *}$ & 0.001 & $0.057^{* * *}$ & 0.001 & $0.074^{* * *}$ & 0.000 & $0.062^{* * *}$ & 0.003 \\
\hline$\varnothing_{22}$ & 0.032 & 0.360 & 0.040 & 0.228 & 0.039 & 0.255 & 0.026 & 0.470 \\
\hline \multicolumn{9}{|c|}{ Panel B. Variance Equation } \\
\hline$c_{11}$ & $0.915^{* * *}$ & 0.000 & $0.232 *$ & 0.057 & $0.390 * * *$ & 0.000 & $0.259^{* * *}$ & 0.009 \\
\hline$c_{21}$ & $0.126^{* * *}$ & 0.001 & 0.049 & 0.132 & 0.033 & 0.553 & $0.089 * *$ & 0.045 \\
\hline$c_{22}$ & 0.000 & 0.865 & 0.000 & 0.799 & 0.058 & 0.237 & 0.051 & 0.320 \\
\hline$\alpha_{11}$ & $0.334^{* * *}$ & 0.000 & $0.452^{* * *}$ & 0.004 & $0.405^{* * *}$ & 0.000 & $0.345^{* * *}$ & 0.004 \\
\hline$\alpha_{12}$ & -0.043 & 0.159 & $0.096^{* *}$ & 0.021 & -0.017 & 0.778 & 0.006 & 0.934 \\
\hline$\alpha_{21}$ & 0.051 & 0.336 & 0.005 & 0.845 & -0.069 & 0.394 & 0.054 & 0.182 \\
\hline$\alpha_{22}$ & $0.236^{* * *}$ & 0.000 & $0.208^{* * *}$ & 0.000 & $0.229^{* * *}$ & 0.000 & $0.256^{* * *}$ & 0.000 \\
\hline$\beta_{11}$ & $0.691^{* * *}$ & 0.000 & $0.844^{* * *}$ & 0.000 & $0.751^{* * *}$ & 0.000 & $0.890^{* * *}$ & 0.000 \\
\hline$\beta_{12}$ & $-0.069 *$ & 0.071 & -0.065 & 0.109 & -0.032 & 0.662 & -0.032 & 0.410 \\
\hline$\beta_{21}$ & $-0.072 *$ & 0.056 & 0.005 & 0.525 & 0.031 & 0.260 & -0.012 & 0.404 \\
\hline$\beta_{22}$ & $0.968^{* * *}$ & 0.000 & $0.978^{* * *}$ & 0.000 & $0.974^{* * *}$ & 0.000 & $0.965^{* * *}$ & 0.000 \\
\hline \multicolumn{9}{|c|}{ Panel C. Diagnostic Tests } \\
\hline $\log L$ & -2506.043 & & -1947.155 & & -2014.255 & & -2107.485 & \\
\hline AIC & 7.227 & & 5.934 & & 5.989 & & 6.295 & \\
\hline SIC & 7.454 & & 6.160 & & 6.216 & & 6.521 & \\
\hline$Q_{1}[20]$ & 21.462 & 0.370 & $29.255^{*}$ & 0.083 & 24.444 & 0.224 & 23.882 & 0.248 \\
\hline$\widetilde{Q}_{2}[20]$ & 23.562 & 0.262 & 27.467 & 0.123 & 24.664 & 0.215 & 26.564 & 0.148 \\
\hline$Q_{1}^{2}[20]$ & 10.480 & 0.959 & $61.006^{* * *}$ & 0.000 & 15.298 & 0.759 & 14.951 & 0.779 \\
\hline$Q_{2}^{2}[20]$ & 21.376 & 0.375 & 27.907 & 0.112 & 25.661 & 0.177 & 20.186 & 0.446 \\
\hline
\end{tabular}

Notes: US, United States of America; CHN, China; BRAZ, Brazil; CHIL, Chile; MEXI, Mexico. Variable order is the Latin American stock market (1) and China (2). In the mean equations and $\mu$ denotes the constant terms, whereas $\varnothing_{12}$ denotes the return spillover from the Latin American stock market to the Chinese stock market. In the variance equation, $\mathrm{c}$ denotes the constant terms, $\alpha$ denotes the ARCH terms, and $\beta$ denotes the GARCH terms. In the variance equation, $\alpha_{12}$ indicates the shock spillover from the Latin American stock market to the Chinese stock market, whereas $\beta_{12}$ denotes the long-term volatility spillover from the Latin American stock market to the Chinese stock market. Number of lags for VAR is decided using the SIC and AIC criteria. JB, Q(20), and $\mathrm{Q}^{2}(20)$ indicate the empirical statistics of the Jarque-Bera test for normality, Ljung-Box $Q$ statistics of order 20 for autocorrelation applied to the standardized residuals, and squared standardized residuals, respectively. Values in parentheses are the $p$-Value. ${ }^{* * *},{ }^{* *}, *$ indicate the statistical significance at $1 \%, 5 \%$, and $10 \%$, respectively.

\subsection{Optimal Weights and Hedge Ratio Portfolio Implications}

In the above-mentioned results, volatility transmission is observed between the several pairs of stock markets during the different sample periods. Thus, investment in these pairs of stock markets reduces the benefit of diversification. Therefore, the risk transmission across stock markets push investors to adjust their asset allocation and to hedge their portfolio risk over time. For this reason, this study estimates the optimal weights and hedge ratios.

Tables 9 and 10 report the optimal weights for the pairs of LA-US and LA-China during all the sample periods. The findings reveal that the optimal weight is 0.11 for BRAZ/US during the full sample period, revealing that for a $\$ 1$ portfolio in Brazil-US, 11 cents should be invested in the Brazil stock market and the remaining 89 cents in the US stock market. The interpretations of all the optimal weights are not interpreted here for the sake of brevity. For the LA-US portfolio (see Table 9), the results show that the average optimal weights are seen to be higher in the global financial crisis and the crash of the Chinese stock market as compared to the full sample period. For the LA-US portfolio, 
the investors are suggested to allocate a higher proportion of investment in LA stocks during the global financial crisis and the crash of the Chinese stock market. For the pair of LA-China (see Table 10), the results show that the optimal weights are higher during the global financial crisis and the crash of the Chinese stock market compared to the full sample period. For the LA-China portfolio, investors should increase their investment in LA stocks during the global financial crisis and the crash of the Chinese stock market.

Table 9. Optimal weights and hedge ratios for Latin America (LA)/US

\begin{tabular}{lcccc}
\hline & BRAZ/US & CHIL/US & MEXI/US & Peru/US \\
\hline \multicolumn{5}{c}{ Full Sample Period } \\
$w_{t}^{L U}$ & 0.11 & 0.51 & 0.29 & 0.27 \\
$\beta_{t}^{L U}$ & 0.93 & 0.63 & 0.25 & 0.28 \\
$w_{t}^{L U}$ & 0.17 & 0.77 & 0.49 \\
$\beta_{t}^{L U}$ & 0.94 & 0.42 & 0.77 & 0.41 \\
$w_{t}^{L U}$ & 0.09 & 0.54 & 0.46 & 0.56 \\
$\beta_{t}^{L U}$ & 0.98 & 0.34 & 0.59 & 0.39 \\
\hline
\end{tabular}

Note: $w_{t}^{L U}$ and $\beta_{t}^{L U}$ represent the optimal weight and hedge ratio for the LA-US pair. $L$ and $U$ in superscripts denote the Latin American and US stock markets, respectively.

Table 10. Optimal weights and hedge ratios for LA/China

\begin{tabular}{lcccc}
\hline Header & BRAZ/CHN & CHIL/CHN & MEXI/CHN & Peru/CHN \\
\hline \multicolumn{5}{c}{ Full Sample Period } \\
$w_{t}^{L C}$ & 0.41 & 0.70 & 0.61 & 0.63 \\
$\beta_{t}^{L C}$ & 0.14 & 0.07 & 0.07 & 0.08 \\
$w_{t}^{L C}$ & 0.53 & US Financial Crisis \\
$\beta_{t}^{L C}$ & 0.21 & 0.81 & 0.68 & 0.63 \\
$w_{t}^{L C}$ & 0.43 & 0.09 & 0.15 & 0.13 \\
$\beta_{t}^{L C}$ & 0.23 & 0.68 & 0.64 & 0.64 \\
\hline
\end{tabular}

Note: $w_{t}^{L C}$ and $\beta_{t}^{L C}$ represent the optimal weight and hedge ratio for LA-China pair. $L$ and $C$ in superscripts denote the Latin American and Chinese stock markets, respectively.

It is also essential to estimate the risk-minimizing optimal hedge ratios for portfolios of different stocks. Referring to Table 9, the optimal hedge ratio range is 0.93 for BRAZ/US during the full sample period, showing that a \$1-long position in Brazil stocks can be hedged for 93 cents with a short position in the US stocks. The interpretations of all the optimal hedge ratios are not interpreted here for the sake of brevity. For the LA-US portfolio (see Table 9), the average optimal hedge ratios are found to be higher for most of the pairs during the global financial crisis and the crash of the Chinese stock market compared to the full sample period. It implies that less LA stocks are needed to minimize the risk of US stock during crisis periods compared to the full sample period. For the LA-China portfolio (see Table 10), the optimal hedge ratios are also higher during both crises, which implies that the lesser LA stocks are required to minimize the risk of the Chinese stock market during both crises compared to the full sample period.

\section{Conclusions}

This study examines the return and volatility spillover between the world-leading (the US and China) and emerging Latin American (Brazil, Chile, Mexico, and Peru) stock markets during the full sample period, the global financial crisis, and the crash of the Chinese stock market. Moreover, this study 
also estimates the optimal weights and hedge ratios during all the sample periods. The BEKK-GARCH model is applied to estimate the return and volatility spillover between the stock markets.

Regarding return spillover, the results reveal a unidirectional return spillover from the US to the majority of the LA stock markets during the full sample period and the Chinese crash. This implies that the US stock market prices play an important role in predicting the prices of the majority of LA stock markets during the full sample period and the Chinese crash. During the global financial crisis, the return transmissions are not significant between the US and the majority of Latin American stock markets. This implies that the prices of the US (LA) stock markets do not contribute to the role of price discovery in the LA (US) stock markets during the global financial crisis. For the China-LA nexus, the results reveal a unidirectional return transmission from China to Brazil, Chile, Mexico, and Peru stock markets during all the sample periods. Thus, the Chinese stock returns can be useful in predicting the returns of the LA stock markets.

Regarding the volatility spillover between the US and LA stock markets, the results reveal the bidirectional volatility transmission between the US and two stock markets of Chile and Mexico, as well as the unidirectional volatility transmission from Brazil to the US stock market during the global financial crisis. During the Chinese crash, a bidirectional volatility transmission is observed between the US and Mexican stock markets. This implies that portfolio investors can diversify risk by making a portfolio of the US and LA stock markets (except Mexico) during the crash of the Chinese stock market.

Regarding the volatility spillover between the China and LA stock markets, the volatility spillover is unidirectional from the China to Brazil stock markets during the global financial crisis. Therefore, the majority of the LA stock markets provide an opportunity to diversify the risk of Chinese equity portfolios during the global financial crisis. During the Chinese crash, the volatility spillover is bidirectional between the China and Brazil stock markets. These findings propose that the portfolio investors of the Chinese stock markets can get the maximum benefit of diversification by adding Mexico, Chile, and Peru stocks to their portfolios during the crash of the Chinese stock market. These findings are also important because understanding the stock market volatility behavior can play a vital role during the valuation of derivatives and for hedging purposes. Moreover, policymakers should consider the "prices and volatilities of the world-leading stock market" as one of the critical factors while devising the policies to stabilize their emerging financial markets.

Based on optimal weights, investors are suggested to allocate a higher proportion of investment to the LA stocks in the LA-US portfolio during the global financial crisis and the crash of the Chinese stock market. For the LA-China portfolio, investors should increase their investment in the LA stocks during the global financial crisis and the crash of the Chinese stock market. Based on hedge ratios, less LA stocks are needed to minimize the risk of the US and Chinese stocks during the periods of both crises compared to the full sample period. Overall, these findings provide useful information for policymakers and portfolio managers regarding optimal asset allocation, diversification, hedging, forecasting, and risk management.

This study employs the BEKK-GARCH model to examine the linkages between the world-leading countries and the emerging Latin American stock markets. Extensions could include other models to examine the return and volatility spillover-for example, cointegration and causality (Lv et al. 2019; Demirer et al. 2019), Copulas (Ly et al. 2019a, 2019b; Yuan et al. 2020), Stochastic Dominance (Chiang et al. 2008; Abid et al. 2014; Guo et al. 2017; Wong et al. 2018), and many others. See, for example, Chang et al. (2018), Woo et al. (2020), and the references therein for more information.

Author Contributions: Conceptulization, estimations, formal analysis, original draft preparation (I.Y.); Data collection, methodology writing, and review of draft (S.A.); review, editing, and funding (W.-K.W.). All authors have read and agreed to the published version of the manuscript.

Funding: The research is partially supported by Asia University, China Medical University Hospital, Hang Seng University of Hong Kong, and the Ministry of Science and Technology (MOST) (Project Numbers 106-2410-H-468-002 and 107-2410-H-468-002-MY3). 
Acknowledgments: The first author gratefully acknowledge Arshad Hassan (Professor/Dean, department of Management and Social Sciences, Capital University of Science and Technology, Islamabad) for their valuable suggestions. The third author would like to thank Robert B. Miller and Howard Thompson for their continuous guidance and encouragement. All the errors remain with the authors.

Conflicts of Interest: The authors declare no conflict of interest.

\section{References}

Abid, Fathi, Pui Leung, Mourad Mroua, and Wing Wong. 2014. International Diversification Versus Domestic Diversification: Mean-Variance Portfolio Optimization and Stochastic Dominance Approaches. Journal of Risk and Financial Management 7: 45-66. [CrossRef]

Ahmad, Wasim, and Sanjay Sehgal. 2015. Regime Shifts and Volatility in BRIICKS Stock Markets: An Asset Allocation Perspective. International Journal of Emerging Markets 10: 383-408. [CrossRef]

Ahmed, Abdullahi D., and Rui Huo. 2019. Impacts of China's Crash on Asia-Pacific Financial Integration: Volatility Interdependence, Information Transmission and Market Co-Movement. Economic Modelling 79: 28-46. [CrossRef]

Aktan, Bora, Pinar Evrim Mandaci, Baris Serkan Kopurlu, and Bulent Ersener. 2009. Behaviour of Emerging Stock Markets in the Global Financial Meltdown: Evidence from Bric-A. African Journal of Business Management 3: 396-404.

Al Nasser, Omar M., and Massomeh Hajilee. 2016. Integration of Emerging Stock Markets with Global Stock Markets. Research in International Business and Finance 36: 1-12. [CrossRef]

Ali, Shoaib, Imran Yousaf, and Muhammad Naveed. 2020. Role of credit rating in determining capital structure: Evidence from non-financial sector of Pakistan. Studies of Applied Economics 38. [CrossRef]

Arouri, Mohamed El Hédi, Amine Lahiani, and Duc Khuong Nguyen. 2015. Cross-Market Dynamics and Optimal Portfolio Strategies in Latin American Equity Markets. European Business Review 27: 161-81. [CrossRef]

Beirne, John, Guglielmo Maria Caporale, Marianne Schulze-Ghattas, and Nicola Spagnolo. 2013. Volatility Spillovers and Contagion from Mature to Emerging Stock Markets. Review of International Economics 21: 1060-75. [CrossRef]

Bekiros, Stelios D. 2014. Contagion, decoupling and the spillover effects of the US financial crisis: Evidence from the BRIC markets. International Review of Financial Analysis 33: 58-69. [CrossRef]

Bhuyan, Rafiqul, Mohammad G. Robbani, Bakhtear Talukdar, and Ajeet Jain. 2016. Information Transmission and Dynamics of Stock Price Movements: An Empirical Analysis of BRICS and US Stock Markets. International Review of Economics \& Finance 46: 180-95.

Bouri, Elie I. 2013. Correlation and Volatility of the MENA Equity Markets in Turbulent Periods, and Portfolio Implications. Economics Bulletin 33: 1575-93.

Cao, Guangxi, Yan Han, Qingchen Li, and Wei Xu. 2017. Asymmetric MF-DCCA Method Based on Risk Conduction and Its Application in the Chinese and Foreign Stock Markets. Physica A: Statistical Mechanics and Its Applications 468: 119-30. [CrossRef]

Cardona, Laura, Marcela Gutiérrez, and Diego A. Agudelo. 2017. Volatility Transmission between US and Latin American Stock Markets: Testing the Decoupling Hypothesis. Research in International Business and Finance 39: 115-27. [CrossRef]

Chancharoenchai, Kanokwan, and Sel Dibooglu. 2006. Volatility Spillovers and Contagion During the Asian Crisis: Evidence from Six Southeast Asian Stock Markets. Emerging Markets Finance and Trade 42: 4-17. [CrossRef]

Chang, Chia-Lin, Michael McAleer, and Roengchai Tansuchat. 2011. Crude Oil Hedging Strategies Using Dynamic Multivariate GARCH. Energy Economics 33: 912-23. [CrossRef]

Chang, Chia-Lin, Michael McAleer, and Guangdong Zuo. 2017. Volatility Spillovers and Causality of Carbon Emissions, Oil and Coal Spot and Futures for the EU and USA. Sustainability 9: 1789. [CrossRef]

Chang, Chia-Lin, Michael McAleer, and Wing-Keung Wong. 2018. Big Data, Computational Science, Economics, Finance, Marketing, Management, and Psychology: Connections. Journal of Risk and Financial Management 11: 15. [CrossRef]

Chen, Gong-Meng, Michael Firth, and Oliver Meng Rui. 2002. Stock Market Linkages: Evidence from Latin America. Journal of Banking \& Finance 26: 1113-41. 
Chiang, Thomas, Hooi Hooi Lean, and Wing-Keung Wong. 2008. Do REITs Outperform Stocks and Fixed-Income Assets? New Evidence from Mean-Variance and Stochastic Dominance Approaches. Journal of Risk and Financial Management 1: 1-40. [CrossRef]

Coleman, Simeon, Vitor Leone, and Otavio R. de Medeiros. 2018. Latin American Stock Market Dynamics and Comovement. International Journal of Finance E Economics 24: 1109-29.

Demirer, Riza, Rangan Gupta, Zhihui Lv, and Wing-Keung Wong. 2019. Equity Return Dispersion and Stock Market Volatility: Evidence from Multivariate Linear and Nonlinear Causality Tests. Sustainability 11: 351. [CrossRef]

Diamandis, Panayiotis F. 2009. International Stock Market Linkages: Evidence from Latin America. Global Finance Journal 20: 13-30. [CrossRef]

Diebold, Francis X., and Kamil Yilmaz. 2012. Better to Give than to Receive: Predictive Directional Measurement of Volatility Spillovers. International Journal of Forecasting 28: 57-66. [CrossRef]

Engle, Robert F., and Kenneth F. Kroner. 1995. Multivariate Simultaneous Generalized ARCH. Econometric Theory 11: 122-50. [CrossRef]

Fang, Lu, and David A. Bessler. 2017. Is It China That Leads the Asian Stock Market Contagion in 2015? Applied Economics Letters 25: 752-57. [CrossRef]

Fernández-Serrano, José L., and Simón Sosvilla-Rivero. 2003. Modelling the Linkages between US and Latin American Stock Markets. Applied Economics 35: 1423-34. [CrossRef]

Fortunato, Graziela, Nathalia Martins, and Carlos de Lamare Bastian-Pinto. 2019. Global Economic Factors and the Latin American Stock Markets. Latin American Business Review 21: 61-91. [CrossRef]

Gamba-Santamaria, Santiago, Jose Eduardo Gomez-Gonzalez, Jorge Luis Hurtado-Guarin, and Luis Fernando Melo-Velandia. 2017. Stock Market Volatility Spillovers: Evidence for Latin America. Finance Research Letters 20: 207-16. [CrossRef]

Garza-García, Jesus Gustavo, and Maria Eugenia Vera-Juárez. 2010. Who influences Latin American stock market returns? China versus USA. International Research Journal of Finance and Economics 55: 22-35.

Graham, Michael, Jarno Kiviaho, and Jussi Nikkinen. 2012. Integration of 22 Emerging Stock Markets: A Three-Dimensional Analysis. Global Finance Journal 23: 34-47. [CrossRef]

Gulzar, Saqib, Ghulam Mujtaba Kayani, Hui Xiaofeng, Usman Ayub, and Amir Rafique. 2019. Financial Cointegration and Spillover Effect of Global Financial Crisis: A Study of Emerging Asian Financial Markets. Economic Research-Ekonomska Istraživanja 32: 187-218. [CrossRef]

Guo, Xu, Xuejun Jiang, and Wing-Keung Wong. 2017. Stochastic Dominance and Omega Ratio: Measures to Examine Market Efficiency, Arbitrage Opportunity, and Anomaly. Economies 5: 38. [CrossRef]

Han, Qian, and Jufang Liang. 2016. Index Futures Trading Restrictions and Spot Market Quality: Evidence from the Recent Chinese Stock Market Crash. Journal of Futures Markets 37: 411-28. [CrossRef]

He, Ling T. 2001. Time Variation Paths of International Transmission of Stock Volatility-US vs. Hong Kong and South Korea. Global Finance Journal 12: 79-93. [CrossRef]

Horvath, Roman, and Petr Poldauf. 2012. International Stock Market Comovements: What Happened during the Financial Crisis? Global Economy Journal 12: 1850252. [CrossRef]

Hwang, Jae-Kwang. 2014. Spillover Effects of the 2008 Financial Crisis in Latin America Stock Markets. International Advances in Economic Research 20: 311-24. [CrossRef]

In, Francis, Sangbae Kim, Jai Hyung Yoon, and Christopher Viney. 2001. Dynamic Interdependence and Volatility Transmission of Asian Stock Markets. International Review of Financial Analysis 10: 87-96. [CrossRef]

Johnson, Robert, and Luc Soenen. 2003. Economic Integration and Stock Market Comovement in the Americas. Journal of Multinational Financial Management 13: 85-100. [CrossRef]

Kroner, Kenneth F., and Victor K. Ng. 1998. Modeling Asymmetric Comovements of Asset Returns. Review of Financial Studies 11: 817-44. [CrossRef]

Kroner, Kenneth F., and Jahangir Sultan. 1993. Time-Varying Distributions and Dynamic Hedging with Foreign Currency Futures. The Journal of Financial and Quantitative Analysis 28: 535. [CrossRef]

Li, Yanan, and David E. Giles. 2014. Modelling Volatility Spillover Effects Between Developed Stock Markets and Asian Emerging Stock Markets. International Journal of Finance $\mathcal{E}$ Economics 20: 155-77.

Lv, Zhihui, Amanda M. Y. Chu, Michael McAleer, and Wing-Keung Wong. 2019. Modelling Economic Growth, Carbon Emissions, and Fossil Fuel Consumption in China: Cointegration and Multivariate Causality. International Journal of Environmental Research and Public Health 16: 4176. [CrossRef] [PubMed] 
Ly, Sel, Kim-Hung Pho, Sal Ly, and Wing-Keung Wong. 2019a. Determining Distribution for the Product of Random Variables by Using Copulas. Risks 7: 23. [CrossRef]

Ly, Sel, Kim-Hung Pho, Sal Ly, and Wing-Keung Wong. 2019b. Determining Distribution for the Quotients of Dependent and Independent Random Variables by Using Copulas. Journal of Risk and Financial Management 12: 42. [CrossRef]

Malik, Farooq, and Shawkat Hammoudeh. 2007. Shock and Volatility Transmission in the Oil, US and Gulf Equity Markets. International Review of Economics \& Finance 16: 357-68.

Markovitz, Harry M. 1959. Portfolio Selection: Efficient Diversification of Investments. Cowles Foundation Monograph 16. London: Yale University Press.

Mensi, Walid, Shawkat Hammoudeh, Duc Khuong Nguyen, and Sang Hoon Kang. 2016. Global Financial Crisis and Spillover Effects among the U.S. and BRICS Stock Markets. International Review of Economics $\mathcal{E}$ Finance 42: 257-76.

Meric, Gulser, Ricardo P. C. Leal, Mitchell Ratner, and Ilhan Meric. 2001. Co-Movements of U.S. and Latin American Equity Markets before and after the 1987 Crash. International Review of Financial Analysis 10: 219-235. [CrossRef]

Ramirez-Hassan, Andres, and Javier Orlando Pantoja. 2018. Co-Movements between Latin American and US Stock Markets: Convergence After the Financial Crisis? Latin American Business Review 19: 157-72. [CrossRef]

Ben Rejeb, Aymen, and Mongi Arfaoui. 2016. Financial Market Interdependencies: A Quantile Regression Analysis of Volatility Spillover. Research in International Business and Finance 36: 140-57. [CrossRef]

Sadorsky, Perry. 2012. Correlations and Volatility Spillovers between Oil Prices and the Stock Prices of Clean Energy and Technology Companies. Energy Economics 34: 248-55. [CrossRef]

Sarwar, Suleman, Aviral Kumar Tiwari, and Cao Tingqiu. 2020. Analyzing Volatility Spillovers between Oil Market and Asian Stock Markets. Resources Policy 66: 101608. [CrossRef]

Sharkasi, Adel, Heather J. Ruskin, and Martin Crane. 2005. Interrelationships among international stock market indices: Europe, Asia and the Americas. International Journal of Theoretical and Applied Finance 8: 603-22. [CrossRef]

Sharma, Gagan Deep, Mandeep Mahendru, and Sanjeet Singh. 2013. Are the Stock Exchanges of Emerging Economies Inter-Linked: Evidence from BRICS. Indian Journal of Finance 7: 26-37.

$\mathrm{Su}$, Xianfang. 2020. Measuring extreme risk spillovers across international stock markets: A quantile variance decomposition analysis. The North American Journal of Economics and Finance 51: 101098. [CrossRef]

Syriopoulos, Theodore, Beljid Makram, and Adel Boubaker. 2015. Stock Market Volatility Spillovers and Portfolio Hedging: BRICS and the Financial Crisis. International Review of Financial Analysis 39: 7-18. [CrossRef]

Taşdemir, Murat, and Abdullah Yalama. 2014. Volatility spillover effects in interregional equity markets: Empirical evidence from Brazil and Turkey. Emerging Markets Finance and Trade 50: 190-202. [CrossRef]

Wang, Gang-Jin, Chi Xie, Min Lin, and H. Eugene Stanley. 2017. Stock Market Contagion during the Global Financial Crisis: A Multiscale Approach. Finance Research Letters 22: 163-68. [CrossRef]

Wong, Wing-Keung, Hooi Lean, Michael McAleer, and Feng-Tse Tsai. 2018. Why Are Warrant Markets Sustained in Taiwan but Not in China? Sustainability 10: 3748. [CrossRef]

Woo, Kai-Yin, Chulin Mai, Michael McAleer, and Wing-Keung Wong. 2020. Review on Efficiency and Anomalies in Stock Markets. Economies 8: 20. [CrossRef]

Yang, Zihui, and Yinggang Zhou. 2017. Quantitative Easing and Volatility Spillovers Across Countries and Asset Classes. Management Science 63: 333-54. [CrossRef]

Yousaf, Imran, and Junaid Ahmed. 2018. Mean and Volatility Spillover of the Latin American Stock Markets. Journal of Business \& Economics 10: 51-63.

Yousaf, Imran, and Arshad Hassan. 2019. Linkages between Crude Oil and Emerging Asian Stock Markets: New Evidence from the Chinese Stock Market Crash. Finance Research Letters 31: 207-17. [CrossRef]

Yuan, Xinyu, Jiechen Tang, Wing-Keung Wong, and Songsak Sriboonchitta. 2020. Modeling Co-Movement among Different Agricultural Commodity Markets: A Copula-GARCH Approach. Sustainability 12: 393. [CrossRef]

(C) 2020 by the authors. Licensee MDPI, Basel, Switzerland. This article is an open access article distributed under the terms and conditions of the Creative Commons Attribution (CC BY) license (http://creativecommons.org/licenses/by/4.0/). 